\title{
A intelectualidade negra e a produção científica: um olhar
}

decolonial

\author{
Betânia de Assis Reis Matta ${ }^{1}$
}

Rita de Cássia Fraga Machado²

\begin{abstract}
Resumo: Este artigo discute o papel feminino na produção de conhecimentos científicos a partir da perspectiva decolonial. Possui como linha de análise a educação libertadora e reflete sobre os discursos sociais contemporâneos pautados em um modelo de pensamento colonialista. Para esse pensamento colonialista, a questão de gênero ainda é muito relevante. A importância deste tema se justifica pela necessidade de compreender os aspectos procedentes da mentalidade colonizadora, que silenciou, censurou e desvalorizou o conhecimento produzido pelas mulheres ao longo da história. Por isso, espaços democráticos de debates devem ser criados para que os grupos que não foram visibilizados durante muito tempo por essa sociedade patriarcal, machista e desigual possam ser ouvidos e acolhidos. Para tanto, a metodologia utilizada foi a pesquisa bibliográfica, tendo como corpus de análise artigos científicos e livros. Os materiais pesquisados fazem referência aos estudos decoloniais e ao legado do Movimento Feminista Negro.
\end{abstract}

Palavras-chave: Gênero - Pensamento decolonial - Educação - Feminismo

\section{The black intellectuality and scientific production: a decolonial view}

\begin{abstract}
This paper discusses the female role in the scientific knowledge production, in a decolonial perspective. It has as guideline the libertarian education, reflecting on contemporary social discourses, based on a colonialist thought model. For the colonialist thinking, the gender issue is still very relevant. This theme importance is justified by the need to understand the aspects from the colonizing mentality, which silenced, censored and depreciated the women knowledge production throughout human history. For this reason, democratic spaces for debate must be created so that groups that have not been seen by this patriarchal, sexist and unequal society can be heard and welcomed. For this research, the bibliographic research methodology was used, having as analysis scientific corpus papers and academic books. The researched materials refer to decolonial studies and the Black Feminism Movement legacy.
\end{abstract}

Keywords: Gender - Decolonial thinking - Education - Feminism

\footnotetext{
${ }^{1}$ Graduada em Serviço Social pela Universidade Federal do Rio de Janeiro (UFRJ). Especialista em criança e adolescente em situação de risco social (UNIFRA - RS) e Gestão Pública (UEA - AM). Mestra em Ciências Humanas pelo Programa de Pós-graduação Interdisciplinar em Ciências Humanas (PPGICH). E-mail: betaniamatta@hotmail.com.

${ }^{2}$ Vice Coordenadora do PPG em Educação da Universidade Estadual do Amazonas - CEST/UEA. É membro da Rede Brasileira de Mulheres Filósofas, da UNESCO - Rede de Mulheres Filósofas da América Latina e do GT - Filosofia e Gênero da ANPOF (2021-2023). Pós-doutora pelo Programa de Pós-Graduação em Educação da Universidade do Vale do Rio dos Sinos. Bolsista PNPD/CAPES. Doutora em Educação pelo Programa de Pós-Graduação em Educação da Universidade Federal do Rio Grande do Sul. O presente trabalho foi realizado com apoio da Coordenação de Aperfeiçoamento de Pessoal de Nível Superior - Brasil (CAPES) - Código de Financiamento 001. E-mail: rmachado@uea.edu.br. http://lattes.cnpq.br/8882999172098781. https://orcid.org/0000-0002-7385-3771.
} 


\section{Introdução}

O processo civilizatório europeu foi permeado por choques culturais que se deram a partir de um processo de dominação pautado no equívoco de considerar a cultura europeia uma ferramenta ideológica e legitimadora de dominação, o que justificou, no seu decurso, sobrepujar por completo a cultura dos povos colonizados. "[...] só a cultura europeia é racional, pode conter sujeitos. As demais não são racionais. Não podem ser nem almejar sujeitos"

Para Césaire ${ }^{4}$, o processo de colonização europeu pode ser entendido como uma equação de extrema desigualdade, em que, de um lado, se observou a dominação europeia e, de outro, a aniquilação de várias culturas. Segundo o autor, a partir "da repressão cultural e do genocídio massivo provenientes do processo de colonização, podemos concluir que a Europa possui uma dívida impagável para com a humanidade, pelas pilhas de cadáveres da história" ". Assim, o contato entre colonizador e colonizado pode ser compreendido como uma total violação dos valores humanos.

De acordo com Quijano ${ }^{6}$, a colonização não significou somente a dominação da cultura ocidental sobre as demais culturas; foi, sobretudo, a dominação do imaginário do colonizado. O que tornou este processo ainda mais perverso. De acordo com o autor, o que se constatou foi a repressão das crenças, dos símbolos, dos conhecimentos dos colonizados, visto que os mesmos não atendiam aos interesses econômicos do sistema colonial. Com isso, os grupos dominados foram coagidos a usar os "padrões de expressão dos dominantes, [...] os quais serviam não somente para impedir a produção cultural dos dominados, mas também como meios muito eficazes de controle social e cultural [...]”7.

Não restam dúvidas que o processo civilizatório europeu ocorreu diante de um cenário de extrema desigualdade e crueldade. A supremacia do homem branco e europeu formou uma combinação que abertamente se consolidou numa relação de dominação. Tal fato permitiu que se estabelecesse uma hegemonia racial e cultural, que se constituiu como instrumento valioso na manutenção e controle do poder nas colônias.

Djamila Ribeiro ${ }^{8}$ aprofunda ainda mais essa questão ao enfocar o protagonismo da mulher negra no período da escravidão, trazendo à luz questões acerca dos processos de resistência e insurgência à dominação europeia, os quais, em sua maioria, são ocultados ou negligenciados pela história oficial. Porém, tais sujeitos configuram-se como sujeitos históricos, fonte de inspiração de ações políticas feministas de descolonização do conhecimento. A autora faz referência também aos efeitos maléficos desencadeados por uma sociedade patriarcal e machista que submeteu as mulheres, em especial as negras, a uma posição social inferior aos homens.

A trajetória das mulheres negras e escravas confirma um cotidiano marcado por circunstâncias de opressão, submissão e exploração sexual, que as forçaram a travar lutas de

\footnotetext{
${ }^{3}$ QUIJANO, "Colonialidad y modernidad-racionalidad", p. 6.

${ }^{4}$ Cf. CÉSAIRE, Discurso sobre o colonialismo.

${ }^{5}$ CÉSAIRE, Discurso sobre o colonialismo, p. 28.

${ }^{6}$ QUIJANO, "Colonialidad y modernidad-racionalidad".

${ }^{7}$ QUIJANO, "Colonialidad y modernidad-racionalidad”, p. 6.

${ }^{8}$ Cf. RIBEIRO, O que é lugar de fala?
} 
resistência diárias, devido a um sistema colonial desumano, consequência do racismo e das desigualdades raciais provenientes do processo civilizatório europeu.

Neste contexto, destacamos a trajetória das lutas do movimento feminino negro, que, por sua vez, reivindica a superação da desigualdade racial e de gênero com o intuito de promover a igualdade de direitos. "Assim, mais do que compartilhar experiências baseadas na escravidão, racismo e colonialismo, essas mulheres partilham processos de resistências".

Ao incentivar a prática de produção de conhecimento científico pelos grupos sociais historicamente apartados da academia, como as mulheres, estamos caminhando rumo a um processo de descolonização do conhecimento, deixando, desta maneira, de sermos objetos de discurso científico para nos tornarmos protagonistas na construção de novos conhecimentos. Isso permite que novas possibilidades de relacionamento com a ciência sejam efetivadas, de forma inovadora e democrática. Em outros termos, descolonizar o conhecimento significa assumir uma postura epistemológica heterogênea, independente e libertadora, ou seja, sair da sombra de um pensamento europeu, que, de certa forma, ainda nos mantém colonizados.

Certamente é um desafio refletir e analisar sobre questões femininas. Todavia, este trabalho se propõe discutir sobre o protagonismo feminino no sistema colonial, bem como a hierarquização de saberes que privilegia a epistemologia eurocêntrica do conhecimento. Por isso a importância da realização de estudos que reivindiquem a emancipação e valorização da produção intelectual negra, rechaçada, ao longo da história, pelo pensamento moderno europeu. O que incitou a manutenção do preconceito, da segregação racial e da desvalorização da cultura negra em uma sociedade que foi constituída de forma desigual.

\section{Movimento feminino negro: a luta pela descolonização do conhecimento}

Para pensarmos a questão do protagonismo feminino negro na busca pela descolonização do conhecimento, é necessário que façamos o esboço de algumas linhas indicativas da trajetória histórica e política dos movimentos de mulheres negras no período colonial. Com isso, proponho aqui um ensaio de ideias que podem, possivelmente, ajudar a compreender a importância da história do movimento negro durante a escravatura.

Neste sentido, Angela Davis ${ }^{10}$ descreve com clareza e objetividade o sofrimento das mulheres negras no período da escravatura estadunidense, cujas práticas podem se estender para a escravatura negra nas colônias do continente americano. Segundo a autora, os escravos eram vistos como bens móveis, considerados apenas como mão de obra rentável, submetidos a condições degradantes e sub-humanas. Destacamos que não havia distinção de gênero na execução das tarefas laborais, ou seja, tanto homens como mulheres eram expostos às mesmas condições severas de trabalho. O que denota que as preocupações dos senhores de escravos se centravam apenas na exploração da força de trabalho, objetivando o lucro.

As mulheres negras trabalhavam como domésticas na casa grande ${ }^{11}$ até completarem a idade para trabalharem nos campos de algodão. Com uma carga horária semelhante à dos homens, trabalhavam no campo do amanhecer ao anoitecer. Não bastando todo esse

\footnotetext{
${ }^{9}$ RIBEIRO, O que é lugar de fala?, p. 17.

${ }^{10}$ Cf. DAVIS, Mulheres, raça e classe.

${ }^{11}$ Como era conhecida a residência da família dos proprietários rurais e de engenho de açúcar no Brasil Colônia.
} 
contexto de violência, ainda eram violentadas sexualmente. A violação era uma prática muito vantajosa para os senhores de escravos, pois não só significava uma estratégia de dominação da população negra escravizada, como os filhos nascidos do estupro equivaliam a uma mercadoria, passível de serem vendidos ou explorados como força de trabalho.

Os comportamentos dos donos de escravos com as mulheres escravas eram: quando era rentável, explorá-las como se fossem homens, sendo observadas, com efeito, sem distinção de gênero, mas quando podiam ser exploradas, castigadas e reprimidas em formas ajustadas apenas às mulheres, elas eram fechadas dentro do seu papel exclusivo de mulheres ${ }^{12}$.

Mesmo diante de vários testemunhos acerca da alta incidência de violação e abuso sexual, a questão nunca foi tratada com o devido empenho, nem pela justiça nem pela literatura especializada. "Vistas como mulheres perdidas e prostitutas, o choro das mulheres negras violadas tinha necessariamente falta de legitimidade". ${ }^{13} \mathrm{Em}$ muitos casos, as mulheres negras foram duplamente vitimizadas, sendo acusadas também de realizarem ações que encorajavam os senhores de escravos à prática do ato sexual, em uma relação permeada por estereótipos negativos acerca das mulheres. Enfim, eram taxadas de infratoras, quando, na verdade, eram vítimas de um sistema desumano e cruel.

Este comportamento é fruto da herança colonial que hipersexualizava a mulher negra, naturalizando-a como um objeto sexual. A literatura, historicamente, se reporta à mulher negra como fogosa, de sexualidade aflorada, destituindo-a por completo de sua condição humana, o que desencadeou um processo de coisificação feminina. Isto alimentou o imaginário dos senhores de escravos com pensamentos permeados de perversidade sexual.

A coação sexual era, antes, uma dimensão essencial das relações sociais entre os donos de escravos e os escravos. Por outras palavras, o direito reclamado pelos donos de escravos e seus agentes sobre os corpos escravos femininos era uma expressão direta dos seus presumidos direitos de propriedade sobre o povo negro como um todo. A licença para violar emanou da facilidade da rude dominação econômica que era o carimbo horrível da escravatura ${ }^{14}$.

Diante de um contexto de permanente violação dos direitos civis e sociais, a luta pela abolição da escravatura passou a ser uma necessidade política. Despertou nas mulheres negras a consciência da sua condição sub-humana, da violência, dos constantes abusos sexuais, da exploração e da opressão sustentada e perpetuada por um regime escravocrata. Esta consciência foi determinante para que elas apoiassem a luta pela abolição da escravatura e contra a discriminação racial.

[...] as mulheres negras eram iguais aos seus homens na opressão que sofreram; elas eram socialmente iguais aos seus homens dentro da

\footnotetext{
${ }^{12}$ DAVIS, Mulheres, raça e classe, p. 11.

${ }^{13}$ DAVIS, Mulheres, raça e classe, p. 132.

${ }^{14}$ DAVIS, Mulberes, raça e classe, p. 128.
} 
comunidade escrava; e elas resistiram à escravatura com uma paixão igual aos seus homens ${ }^{15}$.

A grande ironia do regime escravocrata foi tratar homens e mulheres de forma equiparada, ou seja, não havia distinção de gênero. O que permitiu que experimentassem a igualdade na opressão, na exploração, nas violências físicas, muitas das quais resultavam em mortes. E, considerando ainda a importância dessas mulheres, é necessário lembrar que tiveram um papel de destaque no crescimento econômico das colônias, pois respondiam por atividades no campo, na reprodução de crianças, objetivando novos escravos, e nas funções domésticas da casa grande.

As experiências vivenciadas por elas durante a escravatura as encorajaram a abraçar as causas do movimento antiescravista, dando mais tarde origem à criação do movimento feminino negro. Sua luta pode ser entendida como uma reflexão político-ideológica a partir do seu lugar de fala, ou seja, da posição social que ocuparam na sociedade escravocrata. De acordo com Djamila Ribeiro,

[...] todas as pessoas possuem lugares de fala, pois estamos falando de localização social. E, a partir disso, é possível debater e refletir criticamente sobre os mais variados temas presentes na sociedade. O fundamental é que indivíduos pertencentes ao grupo social privilegiado em termos de locus social consigam enxergar as hierarquias produzidas a partir desse lugar e como esse lugar impacta diretamente na constituição dos lugares de grupos subalternizados ${ }^{16}$.

Neste sentido, o processo de abolição da escravatura representou uma conquista importante. Entretanto, ele não foi suficiente para promover uma descolonização completa da sociedade.

Outro fator preponderante foi a inexistência de políticas públicas que promovessem a inserção do negro na sociedade. Em outros termos, os negros libertos ficaram à mercê de sua própria sorte. Tal fato pode ser observado também no que tange à história da abolição da escravatura no Brasil.

Angela Davis ${ }^{17}$ aponta que, mesmo após quase dois séculos da abolição da escravatura, as mulheres negras continuam a desempenhar os mesmos papéis domésticos de outrora. $\mathrm{O}$ que nos permite concluir que houve um processo de independência, mas que este não foi acompanhado por um processo de descolonização do pensamento dominante. Isto é, a sociedade ainda é marcada por traços de um sistema escravista e patriarcal, mantendo homens e mulheres negros marginalizados, segregados dos espaços de poder social, cultural, econômico, político e educativo.

Um papel tão importante não se cumpre somente através das lutas políticas nos movimentos sociais organizados, mas pode ser feito também através da

\footnotetext{
${ }^{15}$ DAVIS, Mulheres, raça e classe, p. 24.

${ }^{16}$ RIBEIRO, O que é lugar de fala?, p. 48.

${ }^{17} \mathrm{Cf}$. DAVIS, Mulheres, raça e classe.
} 
reflexão científica e da ocupação do espaço conceitual. Ora, até a abolição do regime servil, as massas negras não tiveram acesso à escola e à educação formal e figuravam apenas como objetos de estudos historiográficos, sem poder tomar conhecimento daquilo que se escrevia a seu respeito ${ }^{18}$.

A luta dos negros por um lugar nos bancos escolares, em uma sociedade escravocrata, foi marcada por um processo de banimento social e de exclusão das oportunidades educacionais, que condenou esta população a ações de aniquilamento da capacidade cognitiva e da confiança intelectual. Numa tentativa de deslegitimar as reivindicações pelo reconhecimento da produção cultural negra. Cabe-nos ressaltar que o negro não só teve sua condição humana negada, bem como sua cultura depreciada. Ao longo da história, o que se observou foi a naturalização da exclusão do negro do contexto intelectual.

Ainda hoje, não conseguimos ultrapassar as barreiras impostas por uma educação injusta e desigual, cuja epistemologia se baseia no conhecimento europeu. Em outros termos, somente seremos livres quando rompermos com o modelo epistêmico dominante, ou seja, com a descolonização do conhecimento, permitindo, assim, a abertura de novos espaços para a inserção de intelectuais negras e negros, vislumbrando a construção de uma educação de fato inclusiva. Davis afirma que:

A consequência dessa hierarquização legitimou como superior a explicação epistemológica eurocêntrica conferindo ao pensamento moderno ocidental a exclusividade do que seria conhecimento válido, estruturando-o como dominante e, assim, inviabilizando outras experiências do conhecimento ${ }^{19}$.

A descolonização do conhecimento e a refutação de uma neutralidade epistemológica significam permitir que outros discursos, não hegemônicos, se façam presentes na pesquisa científica praticada no meio acadêmico. Isso possibilita que as vozes subalternizadas a uma epistemologia dominante sejam ouvidas, rompendo, desta forma, com uma história permeada por exclusões. Pontuamos, ainda, que a linguagem dominante sempre foi um instrumento valioso na manutenção de poder, uma vez que invisibilizou grupos sociais, negando-lhes um sistema educacional justo.

Segundo Spivak ${ }^{20}$, a agressão epistêmica corroborou para que se perpetuasse o intelectualismo, que considera poder falar em nome do subalternizado, funcionando como cúmplice do imperialismo, reproduzindo as estruturas de poder e de opressão aos grupos marginalizados. No caso feminino, afirma a autora que "se, no contexto da produção colonial, o sujeito subalterno não tem história e não pode falar, o sujeito subalterno feminino está ainda mais profundamente na obscuridade" 21.

O final do século XX e início do século XXI são marcados por debates que passam a questionar a neutralidade da ciência moderna e seu uso como instrumento de dominação, de discriminação e de racismo. Neste contexto, as contribuições advindas do movimento intelectual negro e dos estudos pós-coloniais ajudaram a desmistificar pseudoteorias raciais

\footnotetext{
${ }^{18}$ MUNANGA, "Prefácio", p. 13.

${ }^{19}$ DAVIS, Mulheres, raça e classe, p. 16.

${ }^{20}$ Cf. SPIVAK, Pode o subalterno falar?

${ }^{21}$ SPIVAK, Pode o subalterno falar?, p. 67.
} 
que atestavam para uma superioridade racial. Todavia, tal reconhecimento não anula os prejuízos sociais e raciais decorrentes do processo histórico. De acordo com Gomes, "tais resultados afetaram não somente o campo da produção intelectual [...], mas de maneira específica, a vida e a trajetória das crianças, adolescentes, jovens, e adultos negros e negras, inclusive na educação"22.

Os intelectuais negros e negras têm como desafio propor um novo olhar científico, que enxergue para além dos aspectos socioeconômicos e passe a compreender a pluralidade cultural, as dimensões simbólicas do preconceito, da desigualdade racial e de gênero, dentre outras. A identidade negra não pode ser compreendida como um grande bloco monolítico de saber monocultural. Entretanto, é possível dialogar com os diferentes perfis intelectuais de origem negra, oriundos de filiações teóricas e políticas diferenciadas, entre jovens negros de diferentes gerações, desde os que adentram na universidade aos militantes políticos do movimento de negritude.

As discussões sobre lugar, perfil e produção dos intelectuais negros nos remetem às reflexões de Santos $^{23}$, que apontam para a necessidade de se estabelecer um diálogo entre os diferentes saberes, evidenciando os conhecimentos que foram silenciados, negligenciados e discriminados. Segundo o autor, é necessário que a ciência seja entendida sob uma perspectiva plural, superando a visão monocultural pautada numa epistemologia eurocêntrica. Para tanto, as contribuições dos movimentos feministas negros, pós-coloniais e multiculturais são de grande valor, visto que estabelecem um diálogo entre a epistemologia convencional da ciência moderna e uma epistemologia construída a partir de outros saberes, alternativos à ciência tradicional.

\section{A intelectualidade negra: um caminho de desafios e resiliências}

O início do século XX foi um divisor de águas na construção e legitimação da identidade intelectual negra, proporcionando reflexões em prol do direito à educação e ao conhecimento no contexto acadêmico brasileiro. O movimento intelectual negro elencou a educação como uma de suas principais bandeiras de luta. Assim, negros e negras, antes apenas objetos de pesquisas científicas, passaram a reivindicar seu espaço como sujeitos produtores de saber. Podemos dizer que este é um longo caminho a ser percorrido diante de um processo histórico marcado por lutas pela equiparação de direitos e pela superação do racismo.

Desse modo, a descolonização do conhecimento exerce um papel primordial, visto que não somente aponta para a necessidade de incluirmos a história da África, de africanos e afro-brasileiros no currículo educacional brasileiro, como possibilita abarcar novas temáticas no âmbito acadêmico. A disciplina rompe com paradigmas dominantes, utilizados pela ciência moderna como instrumentos para justificar a superioridade racial, a discriminação e o racismo. Afirma Gomes: "No decorrer do processo histórico, tais teorias foram derrubadas, superadas e condenadas [...], mas isso não isenta os prejuízos sociais e o

22 GOMES, "Intelectuais negros e produção do conhecimento: algumas reflexões sobre a realidade brasileira", p. 497.

${ }^{23}$ Cf. SANTOS, A gramática do tempo: por uma nova cultura política. 
imaginário racista que elas ajudaram a reforçar e produzir, principalmente, na trajetória de grupos étnico-raciais $[\ldots]^{\prime 24}$.

Os intelectuais negros, no seu discurso, na sua escrita e na sua intervenção no meio acadêmico e literário, elegeram a questão racial como foco de pesquisa e investigação. Gomes $^{25}$ descreve que os negros intelectuais carregam consigo uma ética da convicção do antirracismo, proveniente das reivindicações do movimento negro. Assim, passaram a questionar as relações entre raça e poder, apontando para a existência de uma estrutura em que a dominação racial ainda persiste.

Ao abordarmos acerca da necessidade de democratização dos espaços universitários, pautamos na discussão promovida por Bell $\mathrm{Hooks}^{26}$, quando argumenta que as universidades, mesmo tendo como premissa a busca pela verdade, perdem seu caráter emancipatório: à medida que reproduzem conhecimentos que servem, majoritariamente, a uma elite acadêmica; ao promoverem a hierarquização do saber, pautado no paradigma da ciência moderna; ao desqualificarem debates relacionados às questões sociais concretas, como racismo, desigualdade, preconceito, dominação, segregação racial e poder. Afirma Hooks:

Se examinarmos criticamente o papel tradicional da universidade na busca da verdade e na partilha de conhecimento e informação, ficará claro, infelizmente, que as parcialidades que sustentam e mantêm a supremacia branca, o imperialismo, o sexismo e o racismo distorceram a educação a tal ponto que ela deixou de ser uma prática da liberdade ${ }^{27}$.

As tensões e desafios impostos ao novo perfil de intelectual negro que emerge nos anos 1990 não o impediu de propor ações emancipatórias e de transformação de uma realidade historicamente excludente e discriminatória. Para tanto, é necessário a utilização do conhecimento dito engajado, a fim de subverter teorias eurocêntricas e opressoras presentes no contexto social. "Tal invisibilidade, pois, não é ingênua. Ao contrário, explicita outras faces do racismo e do sexismo vividos por intelectuais negras" 28 .

A questão que se coloca é que os espaços universitários sempre tiveram uma forte preponderância branca e, quando os intelectuais negros passaram a colocar em xeque as pseudoteorias raciais, as estruturas internas da universidade foram abaladas, colocando em foco as relações de poder nela existentes. Cabe-nos apontar que, no Brasil, vivemos o mito da democracia racial e que a nossa academia ainda é marcada pelo predomínio da branquitude. Sobre isso, Gomes alerta:

[...] ao reivindicar o direito ao conhecimento e o direito como produtores de conhecimento, os intelectuais negros desnaturalizam o cânone e ajudam a desvelar o quanto ele sempre foi racial, androcêntrico, eurocêntrico, adultocêntrico e classista. E é esse mesmo potencial de denúncia que exige

\footnotetext{
${ }^{24}$ GOMES, "Intelectuais negros e produção do conhecimento: algumas reflexões sobre a realidade brasileira", p. 497.

${ }^{25}$ GOMES, "Intelectuais negros e produção do Conhecimento: algumas reflexões sobre a realidade brasileira".

${ }^{26}$ Cf. HOOKS, Ensinar a transgredir.

${ }^{27} \mathrm{HOOKS}$, Ensinar a transgredir, p. 45.

${ }^{28}$ SANTIAGO, "Intelectuais negras: entre a invisibilidade e a resistência", p. 59.
} 
desses intelectuais fôlego e competência para produzirem um conhecimento denso que se coloca como alternativa ao cânone e aos ideais da branquitude nele presentes ${ }^{29}$.

Neste sentido, afirmar-se como intelectual negro implica em desvelar a ideologia racista oculta na dominação étnico-racial, que deslegitima os conhecimentos produzidos pelos grupos sociais historicamente discriminados e, por conseguinte, excluídos das práticas acadêmicas e sociais. Enfim, significa reafirmar o compromisso com a mudança social, cultural e política, iniciado no fim do século XIX pelos movimentos intelectuais negros. Inspiramo-nos na fala de Fanon para reforçar nossos argumentos: "Precisamos botar o dedo em todas as chagas que zebram a libré negra" 30 .

Não podemos deixar de destacar que os entraves à intelectualidade negra feminina são mais desafiadores, pois as mulheres negras precisam, além do racismo, lutar ainda contra o sexismo, o que faz com que o caminho se torne mais difícil. De acordo com Djamila Ribeiro, é preciso "divulgar a produção intelectual de mulheres negras, colocando-as na condição de sujeitos e seres ativos que, historicamente, vêm pensando em resistências e reexistências" ’31. Diante desse contexto, sua luta consiste em criar estratégias de superação, permitindo-lhes a merecida visibilidade de sua produção intelectual.

A subordinação sexista e racista na vida das mulheres negras obscurece obras das nossas intelectuais, atuando em paralelo aos estereótipos socialmente construídos da mulher só corpo, sem mente. A insistência cultural com a aceitação dos papéis historicamente sistematizados talvez seja um dos entraves para a visibilização das produções intelectuais negras, contudo, a maior deles é sem dúvida a apropriação dos valores pelas mulheres negras ${ }^{32}$.

Os intelectuais negros e as intelectuais negras, imbuídos dos pensamentos difundidos pelos respectivos movimentos, tomaram para si a luta contra o sistema excludente, racista, sexista e desigual, especialmente no âmbito acadêmico. Desta forma, "o movimento negro pode ser considerado o seu principal lugar de aprendizagem embora não seja necessariamente o seu espaço de atuação política"33.

Ao finalizarmos a presente reflexão, concluímos que a sociedade brasileira é marcada por um racismo velado, que delimita espaços de ocupação para as pessoas ditas "de cor". Com isso, a concepção de educação como prática libertadora se configura como estratégia importante, pois possibilitou a estes intelectuais a compreensão da existência de uma epistemologia dominante, presente não só na sociedade como no meio acadêmico, e que privilegia uma elite predominantemente branca. "Entender esse contexto e construir novas

\footnotetext{
${ }^{29}$ GOMES, "Intelectuais negros e produção do conhecimento: algumas reflexões sobre a realidade brasileira", p. 508.

${ }^{30}$ FANON, Pele negra, máscaras brancas, p. 159.

${ }^{31}$ RIBEIRO, O que é lugar de fala?, p. 9.

32 SOUZA, Mulheres negras e relaçôes de gênero: narrativas de construção da identidade de mulheres negras participantes do Bloco Afro Akomabu do Centro de Cultura Negra do Maranbão, p. 39.

${ }_{33}$ GOMES, "Intelectuais negros e produção do conhecimento: algumas reflexões sobre a realidade brasileira", p. 507.
} 
formas de atuação acadêmica coloca esse grupo de intelectuais diante de velhos e novos desafios" ${ }^{\prime 4}$.

\section{Considerações finais}

Ao refletirmos sobre o movimento negro, devemos ter em mente a importância de suas ações no campo político, social, econômico e, sobretudo, educacional, na busca pela emancipação étnico-racial. Outro fator importante é compreender o processo de colonização europeia a partir da ótica dos estudos pós-coloniais, os quais alargaram as discussões acerca da existência central de uma epistemologia dominante, mantida pela ciência moderna ocidental e pelas relações de poder, em especial, no campo educacional.

A presença, mesmo que de forma velada, de uma epistemologia dominante corroborou para constituir uma sociedade desigual, estimulando a segregação racial, o racismo, a exclusão, a desvalorização da cultura e do conhecimento negro, negando a essa população o seu lugar de fala, tornando-os invisíveis para o contexto social.

A tomada de consciência a partir desta realidade fez com que os negros reivindicassem seu lugar de fala, até então inexistente. Neste contexto, o movimento negro ressignifica e problematiza questões referentes à sua condição étnico-racial, a partir da sua localização social. Atribuímos ao movimento negro:

[...] a luta dos negros na perspectiva de resolver seus problemas na sociedade abrangente, em particular os provenientes dos preconceitos e das discriminações raciais, que os marginalizam no mercado de trabalho, no sistema educacional, político, social e cultural $[. . .]^{35}$.

Nesta perspectiva, a educação passa a ser uma aposta dos movimentos negros na tentativa de estabelecer um diálogo entre os diferentes sujeitos sociais, excluídos historicamente, na busca de reconhecimento como cidadãos. O movimento percebe a educação como propulsora de ações de caráter emancipatório e reivindicatório, necessárias para que negras e negros sejam reconhecidos como sujeitos detentores e produtores de conhecimento.

Todavia, é oportuno destacar que a produção intelectual negra possui uma vasta diversidade cultural, que foi desqualificada historicamente por pseudoteorias que defendiam a inferioridade e a superioridade racial. Tal fato ocasionou perdas significativas no âmbito social, econômico e, principalmente, cultural desta população.

A descolonização do pensamento é uma vertente defendida por intelectuais negros como Aimé Césaire e Frantz Fanon, os quais, a partir de seus estudos pós-coloniais, desvelaram os reais interesses do processo de colonização europeu. Suas ideias foram minuciosamente estudadas, aprofundadas e ampliadas por outros intelectuais, que passaram a investigar e a questionar as heranças coloniais, tendo como eixo o racismo, a segregação racial, a exclusão, a desigualdade social, política e econômica.

\footnotetext{
34 GOMES, "Intelectuais negros e produção do conhecimento: algumas reflexões sobre a realidade brasileira", p. 508.

${ }^{35}$ DOMINGUES, p. 102 apud GOMES, "Movimento negro e educação: ressignificando e politizando a raça", p. 4.
} 
Concluímos destacando o empenho e o esforço dos intelectuais negros que superaram obstáculos estruturais e culturais a fim de inserir a história e a cultura afrobrasileira e africana no currículo escolar brasileiro. Tal passo resulta de práticas educativas de cunho emancipador e transformador da realidade social. O reconhecimento da cultura negra e sua inclusão nos sistemas de ensino oficiais, mesmo que tardiamente, são mais que merecidos. Todavia, é uma jornada que ainda está longe de terminar, pois "a dominação e a opressão continuam a moldar as vidas de todos, sobretudo das pessoas negras e mestiças"

\section{Referências bibliográficas}

CÉSAIRE, Aimé. Discurso sobre o colonialismo. Lisboa: Ed. Sá da Costa, 1978.

DAVIS, Angela. Mulheres, raça e classe. São Paulo: Boitempo, 2016.

FANON, Frantz. Pele negra, máscaras brancas. Salvador: Ed. UFBA, 2008.

GOMES, Nilma Lino. Intelectuais negros e produção do conhecimento: algumas reflexões sobre a realidade brasileira. In: SANTOS. B.; MENEZES, M. (Org.). Epistemologias do Sul. São Paulo: Cortez, 2010. pp. 492-516.

"Movimento negro e educação: ressignificando e politizando a raça". In: Educação e sociedade. Campinas, v. 33, n. ${ }^{\circ} 120$, jul-set 2012.

HOOKS, Bell. Ensinar a transgredir: a educação como prática de liberdade. São Paulo: Martins Fontes, 2017.

MUNANGA, Kabengele. "Prefácio". In: Descolonização do conhecimento no contexto afro-brasileiro. Bahia: UFRB, 2017.

QUIJANO, Anibal. Colonialidad y modernidad-racionalidad. In: BONILLO, H. (Org.). Los conquistados. Bogotá: Tercer Mundo Ediciones; FLACSO, 1992.

RIBEIRO, Djamila. O que é lugar de fala?. Belo Horizonte: Letramento, 2017.

SANTIAGO, Ana Rita. "Intelectuais negras: entre a invisibilidade e a resistência". In: Descolonização do conbecimento no contexto afro-brasileiro. Bahia: UFRB, 2017.

SANTOS, Boaventura de Sousa. A gramática do tempo: por uma nova cultura política. $3^{a}$ ed. São Paulo: Cortez, 2010.

SOUZA, Grace Kelly Silva Sobral. Mulheres negras e relaçoes de gênero: narrativas de construção da identidade de mulheres negras participantes do Bloco Afro Akomabu do Centro de Cultura Negra do Maranhão. Dissertação (Mestrado). Programa de Pós-Graduação em Políticas Públicas da Universidade Federal do Maranhão, São Luís, 2017. Disponível em:

${ }^{36}$ GOMES, "Intelectuais negros e produção do conhecimento: algumas reflexões sobre a realidade brasileira", p. 514. 
http://tedebc.ufma.br:8080/jspui/browse?type $=$ author\&value $=$ Souza $\% 2 C+$ Grace + Kelly + Silva+Sobral. Acesso em 24 abril 2021.

SPIVAK, Gayatri Chakravorty. Pode o subalterno falar?. Belo Horizonte: UFMG, 2010. 